\title{
Knowledge, Experience and Interest on Forensic Medicine in Emergency Nurses
}

\author{
Eunmi Park ${ }^{1}$ and Yeoungsuk Song ${ }^{2}$ \\ ${ }^{1}$ Doctoral Student, Graduate School of Nursing, Kyungpook National University, \\ Daegu, Korea \\ ${ }^{2}$ Associate Professor, College of Nursing, Kyungpook National University, Daegu, \\ Korea \\ ${ }^{1}$ levite73@hanmail.net, ${ }^{2}$ asansong@knu.ac.kr
}

\begin{abstract}
This study was to examine forensic medical knowledge, experience and interest of emergency nurses to administer accurate first aid based on medical decision, to preserve the spot and decisive physical evidence for settlement. The research was carried out to nurses working in the emergency medical center. The structured questionnaire was used with reference to the research tool of Kim and it was analyzed using SPSS WIN 17.0. Frequency, percentage, mean, standard deviation was used. Emergency nurses participated in this study. As to knowledge of forensic medicine, $71.2 \%$ answered the question about cut the cloth and then give first aid. As to the question on the forensic medicine experience; Have you ever seen a patient related to crime? average score was 2.56. The average score on the interest in forensic medicine; Is it necessary to have forensic medical knowledge in the emergency center workers? was 3.36. This study may forensic education for emergency nurses to get evidence of the patient's forensic for accurate initial patient assessment, emergency nurses will need forensic education.
\end{abstract}

Keywords: Forensic, Medicine, Nurse, Knowledge, Experience, Interest

\section{Introduction}

\subsection{Problem statement}

As society has become more developed and more complicated, people who living in the society are experiencing diverse accidents which becoming more spectacular. This phenomenon has changed public understanding of Emergency Medical Services. As people expect more from the Emergency Medical Services, the government of South Korea has commenced a study entitled 'Emergency research on the construction of the medical system' in December 1989 and the government established 129 Emergency Information Centers under the Ministry of Health and Welfare and 119 rescue teams under the municipal governments [1]. As a result of these efforts, additional Emergency Medical facilities have been built to 31 local Emergency Medical Centers, 120 Local Emergency Medical Centers and 262 Local Emergency Medical Facilities in South Korea in December, 2016 [2].

Article history:

Received (October 27, 2017), Review Result (December 14, 2017), Accepted (March 25, 2018) 
In a previous study, $94.8 \%$ of paramedics have experienced taking care of patients related crimes during their duty, and $91.9 \%$ of them have seen crimes related dead [3]. According to the crime information management system report by the Daegu Regional Police Agency, violent crimes the most frequently occurred at 00:00 04:00 which was 8,958 (30.0\%) [4]. As medical services are usually not available at this time, victims of violent crime scenes have to receive immediate first aid services and transported to appropriate Emergency Medical Center. Especially nurses who working in Emergency Medical Center have possibilities to neglect or lose important forensic evidences from victim's clothing or body, if they do not have any knowledge about forensic medicine [5]. Therefore, it may be compulsory obtaining knowledge about forensic medicine for nurses who working in Emergency Medical Center in order to help victims [6].

Furthermore, forensic medicine allows to test criminals' identification by checking bloodstain, hair, sperm, mental assessment and etc. It will help police to find the criminals and protect innocence suspects which in turn, eventually, would prevent occurring the similar crimes [7]. However, there is a lack of understanding of forensic medicine among nurses as well as general public [8].

Therefore, this study to provide a scope of forensic medicine by investigating nurses' understanding of it who working in Emergency Medical Centers. Nurses' current knowledge about forensic medicine, own experiences, and their interest will be used as a data.

\section{Methodology}

\subsection{Design}

This study is a descriptive study to investigate the depth of knowledge about forensic medicine, experience, and interest of nurses working in Emergency Medical Centers

\subsection{Participants}

66 participants were recruited from Emergency Medical Centers from five hospitals located in D city.

\subsection{Method}

Survey questionnaire was used as a study method which developed by Kim [3]. As the questionnaire initially designed for paramedics, some questions were modified for the present study participants. Cronbach'a in this study was .77. The Cronbach'a of knowledge, experience, and interest as sub-factors were $.53, .88$, and .87 respectively.

\subsection{Data collection}

The researchers directly explained the purpose and method of the study to the five nursing departments of the Emergency Medical Center of D City General Hospitals. Written form of informed consent was given to the potential participants which includes the study purpose, method and the rights of the participants such as they can withdraw their participating at any stage and the information will be given by them will be remained anonymous.

\subsection{Analysis}


Corrected data was analyzed using SPSS WIN 17. 0. The general characteristics of the subjects were analyzed using frequency analysis and descriptive statistics to determine the error, percentage, mean, and standard deviation.

\section{Result}

\subsection{General characteristics of subjects}

Academic achievement was $65.2 \%$ for diploma in nursing. Working experience in Emergency Medical Centers was $69.7 \%$ for $1-5$ years. As for the position, general nurse was $84.8 \%$. The following were multiple responses to difficulties during work, with $69.7 \%$ of non-co-ordination of patient and their caregivers [Table 1].

$86.4 \%$ of respondents were interested in forensic medicine because of the influence of TV and media (drama, miniseries, and etc).

Table 1. General characteristics of subjects $(\mathrm{N}=66)$

\begin{tabular}{|c|c|c|c|}
\hline Category & Division & $\mathrm{N}$ & $\%$ \\
\hline \multirow{2}{*}{ Gender } & Male & 5 & 7.6 \\
\hline & Female & 61 & 92.4 \\
\hline \multirow{3}{*}{ Age (yrs) } & $20-29$ & 35 & 53.0 \\
\hline & $30-39$ & 19 & 28.8 \\
\hline & $>40$ & 12 & 18.2.2 \\
\hline \multirow{3}{*}{ Education } & Associated & 43 & 65.2 \\
\hline & Bachelor & 19 & 28.7 \\
\hline & $>$ Master & 4 & 6.1 \\
\hline \multirow{4}{*}{$\begin{array}{c}\text { Emergency Room Experience } \\
(\text { yrs })\end{array}$} & $1-5$ & 46 & 69.7 \\
\hline & $6-10$ & 7 & 10.6 \\
\hline & $11-15$ & 5 & 7.6 \\
\hline & $16-20$ & 2 & 3.0 \\
\hline \multirow{3}{*}{ Title } & Staff nurse & 56 & 84.8 \\
\hline & Charge nurse & 6 & 9.1 \\
\hline & Unit manager & 4 & 6.1 \\
\hline \multirow{6}{*}{$\begin{array}{c}\text { Complaints While Performing } \\
\text { Tasks* }\end{array}$} & Lack of specialized medical knowledge & 15 & 22.7 \\
\hline & Noncooperation of patient's guardian & 46 & 69.7 \\
\hline & Lack of first aid knowledge & 8 & 12.1 \\
\hline & Lack of free time & 40 & 60.6 \\
\hline & Lack of cooperation with other departments & 27 & 40.9 \\
\hline & Other & 4 & 6.1 \\
\hline
\end{tabular}

*Multiple responses

\subsection{Knowledge about forensic medicine}

In terms of forensic evidence acquisition for victims with a stabbed wound, $71.2 \%$ of the participants answered victims' clothes needs to be cut off with scissors prior to applying first aid treatment [Table 2].

\subsection{Experiences in forensic medicine}


The average score of total questions about experiences in forensic medicine was 1.89 out of 5 points. Participants responded to "During work have you experienced an admitted patient related to crime?"

Table 2. Result of knowledge for obtaining forensic medical evidence $(\mathrm{N}=66)$

\begin{tabular}{|c|c|c|c|}
\hline Category & Division & $\mathrm{N}$ & $\%$ \\
\hline \multirow{4}{*}{$\begin{array}{l}\text { Caring for patients with } \\
\text { weapon wound }\end{array}$} & Cut clothes with scissors then perform first aid & 47 & 71.2 \\
\hline & First aid on bleeding site without removing clothes & 10 & 15.2 \\
\hline & Roll up clothes where it's hiding the wound then perform first aid & 5 & 7.6 \\
\hline & Take off clothes without any damage then perform first aid & 3 & 4.5 \\
\hline \multirow{5}{*}{$\begin{array}{l}\text { Cutting clothes on the } \\
\text { bleeding area }\end{array}$} & Fully cut the clothes and remove from the body & 32 & 48.5 \\
\hline & Cut holes and expose the bleeding area & 2 & 3. \\
\hline & Cut bleeding area but avoid holes & 23 & 34.8 \\
\hline & Cut all around the bleeding area with scissors & 8 & 12.1 \\
\hline & Other & 1() & 1.5 \\
\hline \multirow{5}{*}{$\begin{array}{l}\text { Handling clothes cut by } \\
\text { patients }\end{array}$} & Collect it and throw it away in infectious waste & 11 & 16.7 \\
\hline & Collect it then let patient or guardian dispose it & 26 & 39.4 \\
\hline & Do not care & & 1.5 \\
\hline & Turn it over to police officer & 24 & 36.4 \\
\hline & Other & & 6.1 \\
\hline \multirow{9}{*}{$\begin{array}{c}\text { Reasons for not putting } \\
\text { efforts to obtain forensic } \\
\text { evidence* }\end{array}$} & Lack of forensic knowledge & 27 & 40.9 \\
\hline & Feel no need (not nurse-specific job) & 1 & 18.2 \\
\hline & Lack of time (too busy with patient care) & 32 & 48.5 \\
\hline & Lack of workforce & 19 & 28.8 \\
\hline & No need because there are doctors & 4 & 6.1 \\
\hline & Because police officers will arrive soon & 12 & 18.2 \\
\hline & Post-incident statements are inconvenient & 6 & 9.1 \\
\hline & Do not think it is my duty & 5 & 7.6 \\
\hline & Other & 4 & 6.1 \\
\hline
\end{tabular}

* Multiple responses

The average score was 2.56 , which was the highest score among all the questions about experiences in forensic medicine

\subsection{Interest in forensic medicine}

As a result of examining the nurses' interest in forensic medicine, the average score of all items was 3.10 out of 5 points. Participants responded to ". Do you think emergency medical center employees need forensic knowledge?" The average score for the question was 3.36, which was the highest in the total questions about interest.

\section{Discussion}

This study is a descriptive research study to find out the experience, knowledge and interest related to forensic medicine of nurses who working in Emergency Medical Centers. Participants were given a scenario to investigate their knowledge of forensic medicine. When patients visit the Emergency Medical Center with a stabbed wounds (knife, etc.) and severe 
bleeding, $71.2 \%$ of participants answered they would cut the patients' clothes to give initial treatment. In addition, $39.4 \%$ of them said that they would give the removed clothes to patients or their caregivers. There is a similar study argued that $44.4 \%$ of nurses had no idea about forensic medicine, and only $1.6 \%$ of nurses had good understanding of forensic medicine. However, the $1.6 \%$ of nurses were who have already specialized in forensic medicine [9]. Therefore, nurses working in the Emergency Medical Centers may need to get educated about forensic medicine in order to make accurate initial assessment of patients related to crime. Therefore, it may be important to provide nurses who qualified in forensic medicine to secure forensic evidences and identify if patents are related to crime or not.

In terms of the experiences in forensic medicine, the score was 1.89 out of 5 points which means most of the nurses had low forensic medical experience. Also, nurses less often experience child sexual abuse by the score 1.62 points. This is a similar to a report by the Sexual Violence Center demonstrating people try to hide sex offenses as there are always more visitors to get advices than actual number of police notified cases [10]. There may present various factors why nurses less often experience sexual abuse such as the victim being a child, lack of awareness of sexual violence or victims' family member was an offender.

The interest in forensic medicine was 3.10 out of 5 points. Although there is no study presented explored nurses' interest in forensic medicine, level 1 and level 2 paramedics showed their interest by $90.2 \%$ and $91.4 \%$ respectively [3].

\section{Conclusion}

The purpose of this study was to investigate knowledge about forensic medicine, forensic medical experiences and interest of nurses who working in Emergency Medical Centers in order to preserve crime scenes and forensic evidences as well as to provide accurate and prompt first aid treatment for patients. There are some significant results were revealed in this study. In terms of nurses' knowledge about forensic medicine, the answer that achieved highest score was cutting off clothes of patients with a stabbed wound for first aid treatment. In addition, a number of nurses have experienced seeing patients who related crimes at work. Also, the result shows the highest score on the answer that people who work in Emergency Medical Centers may require appropriate knowledge about forensic medicine. As a result of this study, nurses who working in Emergency Medical Centers may need to see victims or criminals as a patient and which can be earlier than police. Hence, nurses showed high interest in learning forensic medicine, and faced needs of the specific knowledge. Therefore, it may be an ideal to teach forensic medicine as a topic in nursing university, and to provide education for nurses who work in Emergency Medical Centers.

\section{References}

[1] J.H. Hwang, "Emergency medical system between hospitals," Journal of the Korean society of emergency medicine, pp.15-24, (1998)

[2] http://www.e-gen.or.kr/nemc/statistics_annual_report.do, Oct 10, (2017)

[3] B.Y. Kim and S.H. Lee, "The educational need of forensic medicine for emergency medical technicians in 119 rescue service,” Journal of Forensic and Investigative Science, vol.2, no.2, pp.50-66, (2007)

[4] S.H. Lee and J.S. Kwak, "Actual conditions of burglaries and analysis on residential invasion burglaries in daegu area," Journal of Forensic and Investigative Science, vol.2, no.2. pp.5-20, (2007)

[5] J. M. Chae, "119 emergency response," Another duty at the crime scene, Education in Gyeongbuk Fire Service Academy, vol.7, pp.69-82, (2003) 
[6] G.Y. Youk and J.S. Kwak, "The role of forensic nurse in the situation of sexual assault," Journal of Forensic and Investigative Science, vol.1, no.1, pp.31-44, (2006)

[7] G.O. Lim, H.K. Park, S.H. Lee, J.S. Kwak, and J.M. Chae, "Current issues on medicolegal death investigation system in Korea and suggestions for future improvement,” Korean Criminological Review, vol.56, pp.247-280, (2003)

[8] E.S. Jung, "Effects of clinical nurses' job stress and emotional laboron job satisfaction," Graduatie School of Public Administration, The catholic university, Seoul, Korea, (2014)

[9] M.H. Han and H.S. Hong, "The awareness and performance of the forensic nursing role in emergency departments,” Korean Society of Biological Nursing Science, vol.14, no.4, pp.291-299, (2012)

[10] J.E. Kim and H.S. Hong, "What characteristics of child sexual abuse cases can affect parents' attitudes to police reporting?" Korean Police Research Association, vol.15, no.1, pp.107-128, (2016) 